\title{
Os pesquisadores, as publicações e os periódicos da área de Finanças no Brasil: Uma análise com base em currículos da plataforma Lattes
}

(The researchers, the publications and the journals of Finance in

Brazil: An analysis based on resumes from the Lattes platform)

\author{
Marcelo Scherer Perlin* \\ André Portela Santos**
}

\section{Resumo}

Este artigo analisa a produção científica da área de Finanças no Brasil. Utilizando um software proprietário para obter informações diretamente da plataforma de currículos Lattes foi possível verificar o perfil e as tendências da pesquisa em Finanças no território nacional. Os principais resultados da pesquisa mostram que a maioria dos pesquisadores de Finanças são relativamente jovens em termos de tempo de carreira, com doutorado finalizado entre os anos de 2005 e 2014 e situados no sudeste do país. Observa-se também que a produção científica nacional em periódicos internacionais de impacto é pequena em comparação com o total de publicações encontradas. O número de publicações por ano tem crescido exponencialmente, porém a qualidade das produções, medida pelo Qualis, deteriorou-se. Uma análise da produtividade dos autores mostra que os autores mais produtivos possuem duas características em comum: doutorado fora do Brasil e bolsa de produtividade do CNPQ.

Palavras-chave: periódicos de finanças; plataforma lattes; pesquisadores de finanças; bolsa de produtividade, bibliometria

Códigos JEL: G00.

Submetido em 5 de março de 2015. Reformulado em 27 de junho de 2015. Aceito em 21 de julho de 2015. Publicado on-line em 5 de Novembro de 2015. O artigo foi avaliado segundo o processo de duplo anonimato além de ser avaliado pelo editor. Editor responsável: Márcio Laurini.

*Universidade Federal do Rio Grande do Sul. E-mail: marcelo.perlin@ufrgs.br

**Universidade Federal de Santa Catarina. E-mail: andre.portela@ufsc.br

Rev. Bras. Finanças (Online), Rio de Janeiro, 13, No. 2, April 2015, pp. 1-xx ISSN 1679-0731, ISSN online 1984-5146

(C)2014 Sociedade Brasileira de Finanças, under a Creative Commons Attribution 3.0 license-

http://creativecommons.org/licenses/by/3.0 


\section{Abstract}

This paper analyzes the scientific output of Finance researchers in Brazil. Using a proprietary software to download information directly from the Lattes platform it was possible to verify the profile and the tendencies of research in the area of Finance in the national territory. The main results of the study show that most of the researchers of Finance are relatively young with respect to their career, with $\mathrm{PhD}$ finished in between the years of 2005 and 2014, and located in the southeastern part of the country. The scientific output of Brazilian researchers in international journals is small in comparison to the total of publications. The number of published papers has risen exponentially, however the quality of the papers, measured by Qualis, has decreased. An analysis of the productivity of the researchers show that the most productive authors have two common attributes: $\mathrm{PhD}$ degree obtained in a foreign institution and the productivity scholarship from CNPQ.

Keywords: finance journals; lattes platform; finance researchers; productivity scholarshipy.

\section{Introdução}

Conceitualmente, define-se Finanças como sendo a ciência do capital, isto é, o estudo da dinâmica de recursos estritamente financeiros em qualquer abrangência de aplicação. Na prática, a área de finanças se preocupa com a defesa destes recursos na análise de riscos e com a alocação inteligente dos mesmos dentro do tópico de investimento e orçamento de capital. Entretanto, conforme aponta Shiller (2013), o grande impacto da área de Finanças em nossa sociedade é no desenvolvimento de arranjos financeiros, isto é, na construção de instrumentos (contratos) financeiros que possibilitam a alocação de capital ocioso em projetos com demanda de recursos. A existência de um desenvolvido mercado financeiro permite que novos projetos e novas tecnologias cheguem ao mercado consumidor, aumentando o nível de produção e emprego, possibilitando assim o avanço de nossa sociedade. A ciência do capital, portanto, promove um dos pilares de uma nação economicamente desenvolvida.

Dada sua importância para a sociedade, o estudo de Finanças justifica-se por promover a análise objetiva de problemas financeiros e buscar oferecer soluções para os mesmos, resultando em uma base teórico-empírica para a ciência do capital. Neste contexto, este artigo tem como interesse estudar o desenvolvimento da ciência de Finanças no Brasil através de uma análise da produção científica dos seus respectivos pesquisadores. Vale observar 
que a pesquisa bibliométrica em Finanças já foi extensamente analisada sobre diferentes aspectos na literatura internacional nos trabalhos de Chung \& Cox (1990), Alexander \& Mabry (1994), Chung et al. (2001), Chen \& Huang (2007), Currie \& Pandher (2011), dentre vários outros. ${ }^{1}$

Para o Brasil, a análise bibliométrica da produção científica nacional em Finanças é recente. O primeiro trabalho neste tópico foi Leal et al. (2003). Utilizando uma amostra de periódicos nacionais e também os anais do principal congresso da área da Administração (Encontro Nacional da ANPAD - Enanpad) de 1980 até 2001, os autores definiram um perfil dos pesquisadores em Finanças: a maioria (70\%) publicou apenas um artigo e a grande parcela das publicações é oriunda dos mesmos autores e das mesmas instituições e estados. Os autores também mensuram a produtividade dos pesquisadores em comparação com o perfil previsto pelo modelo de Lotka (1926), chegando à conclusão de que os pesquisadores brasileiros são menos produtivos que o esperado.

O subsequente trabalho de Camargos et al. (2005) analisou os artigos da área de Finanças apresentados no Enanpad. O trabalho confirma o perfil concentrado dos pesquisadores na região sudeste do Brasil (SP e RJ), mostrando também uma predominância da subárea de Finanças Corporativas entre outras informações. Utilizando uma metodologia semelhante, o trabalho de Camargos et al. (2009) confirma as tendências apontadas no trabalho anterior e mostra também que o número de citações dos trabalhos nacionais é menor em comparação a trabalhos publicados em periódicos internacionais.

No trabalho de Leal et al. (2013) foram novamente analisadas as publicações de diferentes periódicos, utilizando o mesmo método do artigo de Leal et al. (2003), porém inserindo novos periódicos recém criados e considerando também periódicos de outras áreas tal como Engenharia da Produção e Contabilidade, gerando um aumento significativo da base de dados. Leal et al. (2013) analisaram 461 trabalhos de 11 periódicos nacionais de diferentes áreas em comparação com os 260 de 5 periódicos do trabalho anterior. ${ }^{2}$ Os autores confirmam a predominância de trabalhos na área de Finanças Corporativas e também a concentração da produção científica nos estados do Rio de Janeiro e São Paulo. Na análise da produtividade com o modelo de

\footnotetext{
${ }^{1}$ Ver, por exemplo, Cohen et al. (1976), Mabry \& Sharplin (1985), e Niemi (1987).

${ }^{2}$ Excluindo Anais do Enampad e a extinta Revista Brasileira de Mercado de Capitais.
} 
Lotka, os autores novamente concluem que a produção científica nacional da área de Finanças é menor do que o previsto pelo modelo teórico.

Na literatura nacional destaca-se também o trabalho de Rocha et al. (2014) na análise da rede de pesquisadores de Finanças levando em conta as publicações na Revista Brasileira de Finanças (RBFIN) no período de 2003 a 2010 e também o trabalho de Cordeiro et al. (2014) na análise das metodologias empregadas em pesquisas, tendo como fonte de dados as publicações dos periódicos relacionados a Finanças e estratificados no Qualis do ano de 2007 a 2009. ${ }^{3}$ Os autores reportam um aumento da complexidade das metodologias em função do estrato reportado pelo Qualis, isto é, trabalhos publicados em estratos $A 1$ e $A 2$ tendem a implementar metodologias mais complexas.

O presente trabalho pode ser caracterizado como uma extensão dos trabalhos anteriores, principalmente Leal et al. (2003) e Leal et al. (2013). O diferencial do estudo está na abrangência dos dados prospectados para a pesquisa e também na análise da qualidade das publicações. Nossa principal fonte de informação é proveniente da plataforma de currículos Lattes. Portanto, após a identificação dos autores de Finanças, os currículos indicam todas as suas publicações nacionais e internacionais, não sendo necessário restringir ou escolher os periódicos que irão definir a nossa amostra. Além disto, oferecemos uma análise detalhada da qualidade das publicações levando em conta os estratos Qualis da área de Administração e Economia e também toda a publicação Brasileira em periódicos internacionais de impacto da área de Finanças. $\mathrm{O}$ trabalho também investiga os fatores determinantes da produtividade dos pesquisadores, sendo esta uma importante $\mathrm{e}$ inédita análise em relação a literatura já existente.

Para a realização desta pesquisa foi desenvolvido um software proprietário que obtém diretamente da plataforma de currículos Lattes informações a respeito dos currículos dos pesquisadores. O software é chamado NilrepLattes e foi desenvolvido por um dos autores deste artigo. O software está registrado no SEDETEC da UFRGS e pode ser livremente utilizado dentro da esfera pública federal.

\footnotetext{
${ }^{3} \mathrm{O}$ Qualis é o rating do periódicos de acordo com critérios definidos por uma comissão da CAPES. Os periódicos podem ser classificados em nível decrescente de qualidade: A1, A2, B1, B2, B3, B4 e C. Esta classificação tem caráter reativo, isto é, quando um periódico não classificado é inserido em relatórios de avaliação de programas de pós-graduação da CAPES, o mesmo é classificado e adicionado ao Qualis.
} 
Os resultados da pesquisa confirmam alguns resultados dos trabalhos anteriores tal como a predominância de autores entre São Paulo e Rio de Janeiro e a informação de que a RBFIN (Revista Brasileira de Finanças) é o principal veículo de publicação científica na área de Finanças no país, com o maior número de publicações entre os pesquisadores selecionados. As publicações internacionais dos pesquisadores brasileiros em periódicos de impacto representam uma pequena proporção em relação ao total publicado, porém de alta qualidade por critérios internacionais. Reportamos também que o número de pesquisadores e artigos vem crescendo de forma exponencial ao longo dos anos, porém a qualidade dos mesmos vem decrescendo, mostrando uma sistemática preferência por quantidade e não por qualidade. Uma análise estatística da produtividade em pesquisa mostra que os pesquisadores mais produtivos possuem duas características em comum, bolsa de produtividade do CNPQ e doutorado fora do país, sendo estas de profunda relevância na definição de políticas públicas para o incentivo da ciência Brasileira.

\section{Dados}

Em agosto de 1990 o Governo Federal padronizou a estruturação de currículos acadêmicos no sistema Lattes. O preenchimento do Lattes é um requisito para todo pesquisador situado em instituições brasileiras, tanto para o pleito de bolsas e financiamento de pesquisa como também para as progressões funcionais de carreira e avaliação de programas de pós-graduação. Este sistema representa a principal fonte de informação sobre a trajetória profissional de um pesquisador no Brasil. A importância da plataforma de currículos Lattes na medição da produção científica foi reconhecida internacionalmente pela renomada revista Nature em Lane (2010).

Dada a sua importância dentro do sistema acadêmico, o Lattes consagra-se como uma ótima fonte de dados para a análise bibliométrica de determinada área. O presente artigo utilizou-se de uma vasta base de dados da plataforma Lattes para atingir os seus objetivos. O primeiro passo foi acessar os dados sobre pesquisadores, incluindo nome e link do Lattes, para determinadas áreas dentro do site http://lattes.cnpq.br/ (acessado em 05/03/2015). Nesta primeira parte, o único filtro utilizado foi que os pesquisadores tenham título de doutor e estejam vinculados a uma instituição brasileira. A partir desta lista, utilizou-se o software proprietário Nilrep- 
Lattes para baixar dados dos currículos Lattes de cada pesquisador.

A área de Finanças é interdisciplinar por natureza, envolvendo diferentes áreas de conhecimento tal como Administração de Empresas, Economia, Estatística dentre várias outras. Porém, claramente existem áreas mais afins a Finanças que outras. Para o presente trabalho, as áreas utilizadas para o acesso aos currículos Lattes foram Administração de Empresas (ADM), Economia (ECON), Engenharia de Produção (ENGPROD), Estatística (ESTAT) e Matemática (MAT) (Leal et al., 2013). Importante também destacar que a área de Contabilidade foi adicionada implicitamente pois a plataforma Lattes considera Ciências Contábeis como uma subárea de Administração. A Tabela 1 a seguir apresenta a quantidade de pesquisadores cujos currículos foram acessados via a plataforma Lattes, além de outras informações.

Tabela 1: Estatísticas de produção científica das cinco áreas relacionadas a Finanças

A tabela reporta as estatísticas de produção científica para as diferentes áreas relacionadas a Finanças. Os dados foram coletados diretamente da plataforma Lattes e as estatísticas foram calculadas com base nas publicações e outras informações encontradas para cada pesquisador registrado nas diferentes áreas de conhecimento.

\begin{tabular}{lccccc}
\hline Área & ADM & ECON & ENGPROD & ESTAT & MAT \\
\hline Número de pesquisadores & 9.336 & 5.448 & 4.355 & 2.851 & 5.456 \\
Número de artigos publicados & 95.595 & 59.281 & 47.263 & 50.593 & 48.219 \\
Média de artigos por pesquisador & 10,24 & 10,88 & 10,85 & 17,75 & 8,84 \\
Média do número de páginas & 14,22 & 16,00 & 11,80 & 9,67 & 12,65 \\
Média do número de autores & 2,95 & 2,48 & 3,37 & 4,29 & 3,03 \\
$\%$ de pesq.com bolsa de produtividade & $3,10 \%$ & $6,20 \%$ & $7,42 \%$ & $9,96 \%$ & $9,20 \%$ \\
$\%$ de pesq. com doutorado fora do Brasil & $16,93 \%$ & $20,98 \%$ & $13,80 \%$ & $18,13 \%$ & $15,12 \%$ \\
\hline
\end{tabular}

Conforme pode ser visto na Tabela 1, a área de Administração de empresas é comparativamente maior em relação às demais, com 9.336 currículos Lattes cadastrados. Pode-se explicar tal resultado pelo grande número de programas de pós-graduação e também pela forte interdisciplinaridade na área de Administração, resultando em um contingente maior de pesquisadores. Vale salientar, porém, que um pesquisador pode estar cadastrado em até cinco áreas diferentes no Lattes, de modo que os valores definidos na Tabela 1 podem contar o mesmo pesquisador em mais de uma área.

Os valores da Tabela 1 indicam claramente diferenças entre as características específicas das áreas. A área de Estatística, por exemplo, apresenta a maior média de número de publicações por pesquisadores, a menor média de número de páginas por trabalho e a maior média de autores por trabalho. 
Observa-se também a maior internacionalização dos professores nas áreas de Economia e Estatística, com respectivamente 20,98\% e 18,13\% de pesquisadores com doutorado fora do país. Ademais, analisando as percentagens de professores com bolsa de produtividade, observa-se que para as áreas de ciências exatas (ENGPROD, ESTAT, MAT) esta percentagem é maior do que para as áreas de sociais aplicadas (ADM e ECON). As estatísticas apresentadas na Tabela 1 podem ser particularmente interessantes para o suporte de políticas públicas na área de educação e pesquisa e certamente instigam a curiosidade a respeito das diferenças entre as áreas de conhecimento.

A partir dos 27.446 currículos dos pesquisadores, o próximo passo da pesquisa foi identificar os pesquisadores de Finanças e suas respectivas produções científicas. É importante ressaltar que este é um ponto crucial do trabalho pois uma má identificação pode caracterizar erroneamente a área. Nos trabalho anteriores de Leal et al. (2003) e Leal et al. (2013) os autores foram identificados a partir das publicações em uma lista restrita de periódicos da área de Finanças. Para aqueles periódicos que também publicam artigos de outras áreas, o método utilizado pelos autores foi analisar o títulos das publicações e assim determinar se o artigo pertence à área de finanças ou não. O ponto forte desta abordagem é a sua simplicidade. Os seus pontos fracos, entretanto, são a subjetividade com que os artigos são classificados e também o trabalho necessário para executar a identificação dos artigos e autores de Finanças. No presente artigo, a quantidade de dados motiva a utilização de um método mais objetivo para identificar os pesquisadores de Finanças, o qual possa ser facilmente aplicado em larga escala e também replicado em outras área de conhecimento que sejam interdisciplinares.

O método escolhido é semelhante ao utilizado em Leal et al. (2013), porém mais flexível quanto aos periódicos. Concretamente, o primeiro passo foi selecionar da amostra todos os pesquisadores que apresentassem no mínimo uma das palavras a seguir: Finanças, Financeira, Finance e Financial na descrição dos seus currículos Lattes. Após isto, a amostra foi restringida a apenas aqueles autores que possuem mais de $10 \%$ de sua produção científica em periódicos cujo nome possua no mínimo uma das palavras destacadas anteriormente.

A amostra foi novamente filtrada removendo-se todos os autores que possuem mais de $25 \%$ de sua produção científica em periódicos com a palavra 
Contabilidade ou Accounting em seu nome. Utiliza-se esta última regra com o objetivo de retirar da amostra os pesquisadores da área de Contabilidade que tenham pouca inserção na área de Finanças. Por fim, exclui-se da amostra todos os pesquisadores que não possuíam no mínimo um artigo publicado e todas as publicações sem o registro do respectivo ISSN (International Standard Serial Number) do periódico. Após a filtragem, a base de dados contém 174 pesquisadores, 2.250 publicações e 708 periódicos diferentes. Estes valores são contrastantes com os 11 periódicos e os 461 artigos analisados em Leal et al. (2013). Por fim, vale ressaltar que esta base de dados com a identificação e as publicações dos pesquisadores de Finanças selecionados na amostra utilizada neste trabalho está disponibilizada na página pessoal do primeiro autor.

É importante observar que a definição dos limites para a escolha dos pesquisadores foi subjetiva. Entretanto entende-se que os limites definidos foram razoáveis. Para entender o impacto desta decisão, apresentamos na Tabela 2 o número de pesquisadores selecionados em função do limite estabelecido para a identificação dos mesmos. Na Tabela, as linhas representam as mudanças no limite relacionado ao critério de seleção de pesquisadores da área de Finanças (autores que possuem um percentual mínimo de sua produção científica em periódicos cujo nome possua no mínimo uma das seguintes palavras: Finanças, Financeira, Finance e Financial, enquanto que as colunas representam as mudanças para o limite relacionado ao critério de seleção de pesquisadores da área de Contabilidade (autores que possuem um percentual mínimo de sua produção científica em periódicos com a palavra Contabilidade ou Accounting). Observa-se que enquanto o aumento do limite relacionado à área de Finanças diminui o número de pesquisadores, o limite relacionado à área de Contabilidade flexibiliza a filtragem e aumenta o número de pesquisadores incluídos na amostra.

Os valores apresentados na Tabela 2 mostram que o uso dos limites aumenta e diminui a amostra de forma considerável. Por exemplo, adotando-se um limite mínimo de 5\% de periódicos com as palavras relacionadas a Finanças diminui consideravelmente o número de pesquisadores, de 1.369 para 164. Vale salientar que a todas as análises também foram executadas com base em outros limites além dos 10\% (Finanças) e 25\% (Contabilidade) adotados no trabalho. Os resultados obtidos são semelhantes e podem ser disponibilizados caso haja interesse. 
Tabela 2: Número de pesquisadores incluídos na amostra em função dos limites de identificação das áreas de Finanças e Contabilidade

A tabela reporta o número de pesquisadores encontrados em função da utilização de diferentes limites no encontro das palavras relacionadas a Finanças e Contabilidade. As linhas indicam a mudança no limite mínimo na proporção de periódicos que contenham uma das seguintes palavras: Finanças, Finance, Financeira e Financial, enquanto as colunas reportam as mudanças no limite máximo da proporção de periódicos cujo nome contenha uma das seguintes palavras relacionadas a Ciências Contábeis: Contabilidade ou Accounting.

\begin{tabular}{|c|c|c|c|c|c|c|c|c|c|c|c|}
\hline \multirow[b]{2}{*}{ Limite "Finanças" } & \multicolumn{11}{|c|}{ Limite "Contabilidade" } \\
\hline & $0 \%$ & $5 \%$ & $10 \%$ & $15 \%$ & $20 \%$ & $25 \%$ & $30 \%$ & $35 \%$ & $40 \%$ & $45 \%$ & $50 \%$ \\
\hline $0 \%$ & 1.369 & 1.415 & 1.473 & 1.521 & 1.555 & 1.575 & 1.598 & 1.626 & 1.656 & 1.673 & 1.721 \\
\hline $5 \%$ & 164 & 177 & 195 & 213 & 222 & 229 & 237 & 245 & 256 & 261 & 275 \\
\hline $10 \%$ & 128 & 136 & 146 & 160 & 168 & 174 & 182 & 186 & 193 & 196 & 204 \\
\hline $15 \%$ & 96 & 101 & 107 & 110 & 118 & 122 & 129 & 133 & 137 & 138 & 143 \\
\hline $20 \%$ & 83 & 86 & 90 & 93 & 99 & 103 & 107 & 109 & 113 & 114 & 118 \\
\hline $25 \%$ & 70 & 71 & 73 & 75 & 77 & 80 & 80 & 82 & 84 & 85 & 89 \\
\hline $30 \%$ & 57 & 57 & 58 & 58 & 60 & 62 & 62 & 64 & 66 & 67 & 70 \\
\hline $35 \%$ & 43 & 43 & 43 & 43 & 45 & 45 & 45 & 45 & 46 & 46 & 49 \\
\hline $40 \%$ & 40 & 40 & 40 & 40 & 42 & 42 & 42 & 42 & 43 & 43 & 46 \\
\hline $45 \%$ & 33 & 33 & 33 & 33 & 34 & 34 & 34 & 34 & 34 & 34 & 37 \\
\hline $50 \%$ & 33 & 33 & 33 & 33 & 34 & 34 & 34 & 34 & 34 & 34 & 37 \\
\hline
\end{tabular}

\section{Resultados}

A estrutura da apresentação dos resultados foi simplificada pela separação dos tópicos de interesse. Neste caso, divide-se a análise entre os pesquisadores, os periódicos e as publicações.

\subsection{Os pesquisadores}

A Figura 1 apresenta algumas estatísticas obtidas a partir da base de dados construída com os critérios definidos na Seção 2. Na Figura, o painel (a) indica a quantidade de pesquisadores entre as diferentes áreas afins. Conforme esperado, verifica-se que as áreas de Administração e Economia são aquelas com o maior número de pesquisadores, com 103 e 106 pesquisadores vinculados à área de Finanças, respectivamente. Vale salientar que o somatório do número de pesquisadores em todas as áreas não é equivalente aos 174 pesquisadores distintos pois cada um pode escolher até cinco áreas diferentes dentro da plataforma de currículos Lattes. A Figura também permite identificar a idade acadêmica dos pesquisadores a partir do seu ano de doutoramento. Na grande maioria dos casos, a vida profissional de um pesquisador tende a começar quando o mesmo termina o doutorado. $\mathrm{O}$ histograma apresentado no painel (b) da Figura 1 mostra que a maior quan- 
tidade de pesquisadores é recém doutorada, com ano de término após 2005. No painel (c) da Figura 1 vemos que o tempo necessário para o término do doutorado é em torno de 3 a 4 anos. Verifica-se também que os dados obtidos junto a plataforma Lattes estão atualizados, uma vez que a grande maioria dos pesquisadores fez a última atualização em dezembro de 2014, sendo que os dados foram coletados pelo software no início de janeiro de 2015.

Figura 1: Estatísticas sobre Publicações em Finanças no Brasil

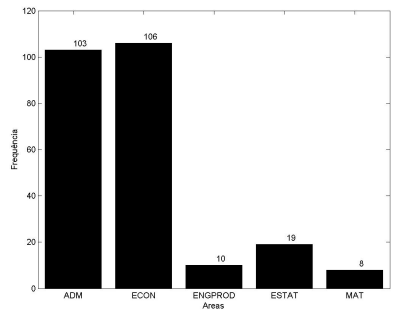

(1) Número de pesquisadores por área

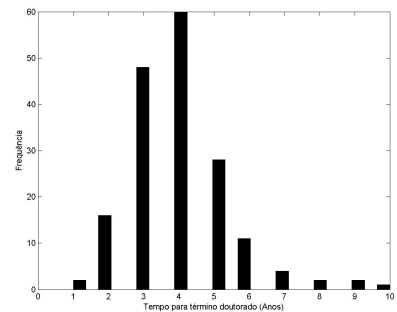

(3) Frequência do tempo para término de Doutorado)

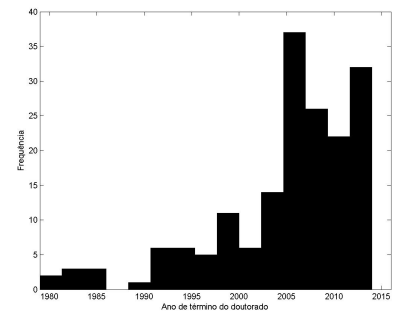

(2) Frequência do ano de término do Doutorado

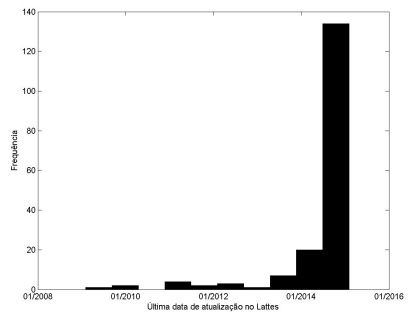

(4) Frequência da última atualização do Lattes

Para fins de identificação da localização geográfica dos pesquisadores, nas Tabela 3 e 4 apresentam-se as cinco cidades e cinco estados, respectivamente, com o maior número de pesquisadores de Finanças. Conforme esperado, os valores nas Tabelas 3 e 4 mostram claramente a tendência dos pesquisadores estarem localizados no Sudeste do Brasil, especialmente nos estados de Rio de Janeiro e São Paulo (Leal et al., 2003, 2013). Observa-se que o trio SP-RJ-DF representa uma parcela significativa do número de pesquisadores. Os dados mostram que estes três estados possuem 56,32\% dos pesquisadores e $70 \%$ do total de publicações, sugerindo uma concentração 
de pesquisadores e da produtividade científica nacional na área de Finanças. Vale notar que a composição majoritária nos Estados de Rio de Janeiro e São Paulo não é acidental. As maiores escolas de negócios e de Economia, assim como o centro financeiro do país, estão localizados nestes Estados. Para o caso de Brasília-DF observa-se a existência de diversas instituições de pesquisa tal como o IPEA e o BACEN.

As Tabelas 3 e 4 também reportam, por cidade e por Estado, respectivamente, o percentual de pesquisadores com bolsa de produtividade em pesquisa do CNPQ e o percentual de publicações que possuem fator de impacto medido pelo JCR - Journal Citation Report desenvolvido pela Thomsom Reuters. Este indicador mede a frequência média com que um artigo em determinado periódico tem sido citado em um ano. ${ }^{4}$ É consenso entre grande parte dos pesquisadores que aqueles periódicos que possuem $J C R$ são considerados de melhor qualidade em relação aos periódicos que não possuem, em função de sua maior inserção no meio acadêmico. Além disso, quanto maior o $J C R$ de um periódico, maior é sua qualidade e seu prestígio perante a comunidade acadêmica. As Tabelas 3 e 4 indicam que nos Estados de SP e RJ e no DF a proporção de pesquisadores com bolsa de produtividade e com publicações em periódicos com JCR é superior a $15 \%$.

\subsection{Os periódicos}

Nesta etapa da pesquisa verifica-se em quais periódicos os pesquisadores publicaram suas pesquisas, assim como a quantidade de artigos publicados em cada periódico. Vale observar que o número de periódicos contemplados neste estudo é substancialmente maior em relação ao considerado em estudos anteriores como, por exemplo, Leal et al. (2003) e Leal et al. (2013). A Tabela 5, apresenta os 25 periódicos com o maior número de publicações, assim suas respectivas classificações no Qualis das áreas de Administração de Empresas e Economia, as quais representam a maior

\footnotetext{
${ }^{4}$ Informações adicionais a respeito da metodologia de construção do fator de impacto $J C R$ podem ser obtidam em http://thomsonreuters.com/content/ dam/openweb/documents/pdf/scholarly-scientific-research/fact-sheet/ esi-jcr-brochure.pdf (acessado em 05/03/2015)
}

172 Rev. Bras. Finanças (Online), Rio de Janeiro, V13, No. 2, April 2015 
Tabela 3: As dez cidades brasileiras com os maiores número de pesquisadores na área de Finanças

A tabela reporta as dez cidades brasileiras com o maior número de pesquisadores de Finanças e a respectiva soma do número de publicações, o percentual de bolsistas de produtividade e também o percentual de publicações indexadas ao JCR. Os dados de endereço utilizados para construir a tabela foram coletados diretamente do Lattes de cada pesquisador, no campo Endereço para correspondência no Lattes.

\begin{tabular}{lcccc}
\hline Cidade & \# Pesquisadores & \# Publicações & \% de bolsistas produtividade & \% de Publicações indexadas ao JCR \\
\hline São Paulo-SP & 37 & 525 & $18,92 \%$ & $16,38 \%$ \\
Rio de Janeiro-RJ & 26 & 551 & $23,08 \%$ & $17,60 \%$ \\
Brasília-DF & 25 & 366 & $16,00 \%$ & $25,68 \%$ \\
Porto Alegre-RS & 8 & 93 & $12,50 \%$ & $8,60 \%$ \\
Belo Horizonte-MG & 5 & 76 & $20,00 \%$ & $6,58 \%$ \\
Curitiba-PR & 3 & 14 & $0,00 \%$ & $13,24 \%$ \\
Florianópolis-SC & 3 & 68 & $66,67 \%$ & $0,00 \%$ \\
João Pessoa-PB & 3 & 16 & $0,00 \%$ & $17,05 \%$ \\
Ribeirão Preto-SP & 3 & 88 & $33,33 \%$ & $20,00 \%$ \\
Vitória-ES & 3 & 35 & $0,00 \%$ & \\
\hline
\end{tabular}

Tabela 4: Os dez estados brasileiros com os maiores números de pesquisadores na área de Finanças

A tabela reporta os dez estados brasileiros com o maior número de pesquisadores de Finanças e a soma do número de publicações, o percentual de bolsistas de produtividade e também o percentual de publicações indexadas ao JCR. Os dados de localização dos diferentes pesquisadores foram coletados no campo Endereço para correspondência no Lattes.

\begin{tabular}{lcccc}
\hline Estado & \# Pesquisadores & \# Publicações & \% de bolsistas com produtividade & \% de Publicações indexadas ao JCR \\
\hline SP & 47 & 658 & $17,02 \%$ & $15,50 \%$ \\
RJ & 26 & 551 & $23,08 \%$ & $17,60 \%$ \\
DF & 25 & 366 & $16,00 \%$ & $25,68 \%$ \\
RS & 13 & 200 & $15,38 \%$ & $7,50 \%$ \\
MG & 11 & 123 & $9,09 \%$ & $11,38 \%$ \\
PR & 4 & 17 & $0,00 \%$ & $20,00 \%$ \\
ES & 3 & 35 & $0,00 \%$ & $0,00 \%$ \\
PB & 3 & 16 & $0,00 \%$ & $13,24 \%$ \\
SC & 3 & 68 & $66,67 \%$ & $0,00 \%$ \\
BA & 2 & 12 & $0,00 \%$ & \\
\hline
\end{tabular}


proporção dos vínculos dos pesquisadores em Finanças. A Tabela 5 foi criada a partir da contagem das publicações dos autores tendo em vista cada um dos periódicos encontrados. 
Tabela 5: Os 25 periódicos com o maior número de publicações de pesquisadores em Finanças no Brasil

A tabela apresenta os 25 periódicos com o maior número de publicações pelos pesquisadores identificados na amostra segundo os critérios definidos na seção 2. Os estrato do Qualis é reportado para a área de Administração e Economia. Aqueles periódicos sem estrato no Qualis ADM ou ECON são identificados por “-”. A contagem do número de pesquisadores diferentes para ambas as áreas e também para as demais áreas (ESTAT, MAT e ENGPRD) também é apresentada.

\begin{tabular}{|c|c|c|c|c|c|c|}
\hline Nome & Qualis ADM & Qualis ECON & \# pub. & \# Pesq ADM & \# Pesq ECON & \# Outras \\
\hline Revista Brasileira de Finanças & B1 & $\mathrm{B} 2$ & 116 & 42 & 42 & 46 \\
\hline Revista Brasileira de Economia & A2 & B1 & 59 & 15 & 31 & 31 \\
\hline Revista de Administração (FEA-USP) & A2 & $\mathrm{B} 2$ & 59 & 22 & 8 & 10 \\
\hline RAE (Impresso) & $\mathrm{A} 2$ & B4 & 48 & 20 & 4 & 6 \\
\hline Physica. A (Print) & A1 & $\mathrm{B} 2$ & 41 & 1 & 5 & 5 \\
\hline Journal of International Finance and Economics & $\mathrm{C}$ & B5 & 39 & 10 & 5 & 7 \\
\hline Economia Aplicada (Impresso) & B1 & B1 & 35 & 10 & 18 & 19 \\
\hline Pesquisa e Planejamento Econômico (Rio de Janeiro) & B3 & $\mathrm{B} 1$ & 28 & 3 & 15 & 15 \\
\hline Revista de Econometria & - & $\mathrm{B} 1$ & 28 & 4 & 14 & 15 \\
\hline Revista de Economia e Administração & B3 & B3 & 28 & 17 & 12 & 13 \\
\hline BBR. Brazilian Business Review & $\mathrm{A} 2$ & B5 & 27 & 17 & 12 & 13 \\
\hline Corporate Ownership \& Control (Print) & B3 & $\mathrm{C}$ & 26 & 7 & 3 & 3 \\
\hline Journal of Banking \& Finance (Print) & A1 & $\mathrm{A} 2$ & 25 & 8 & 14 & 14 \\
\hline RAC. Revista de Administração Contemporânea & $\mathrm{A} 2$ & B4 & 24 & 16 & 3 & 4 \\
\hline Revista de Finanças Aplicadas & B3 & B5 & 24 & 20 & 5 & 6 \\
\hline REAd. Revista Eletrônica de Administração & $\mathrm{B} 1$ & B3 & 23 & 13 & 2 & 4 \\
\hline Estudos Econômicos (São Paulo. Impresso) & B1 & $\mathrm{B} 1$ & 21 & 8 & 14 & 14 \\
\hline Review of Business Research & $\mathrm{C}$ & B4 & 19 & 5 & 1 & 3 \\
\hline Chaos, Solitons and Fractals & - & B1 & 18 & 1 & 4 & 4 \\
\hline BAR. Brazilian Administration Review & $\mathrm{A} 2$ & B3 & 18 & 14 & 4 & 4 \\
\hline RAM. Revista de Administração Mackenzie & $\mathrm{B} 1$ & B3 & 17 & 12 & 7 & 9 \\
\hline RAM. Revista de Administração Mackenzie (Online) & $\mathrm{B} 1$ & B3 & 17 & 11 & 5 & 5 \\
\hline Latin American Business Review & B1 & B3 & 16 & 8 & 3 & 5 \\
\hline Journal of Academy of Business and Economics & $\mathrm{C}$ & B3 & 16 & 5 & 2 & 4 \\
\hline Emerging Markets Review & A1 & $\mathrm{B} 2$ & 16 & 6 & 9 & 10 \\
\hline
\end{tabular}


A Tabela 5 confirma que a Revista Brasileira de Finanças (RBFIN) é o principal periódico de Finanças no Brasil, com um total de 116 artigos publicados por todos os pesquisadores, sendo que observa-se 42 pesquisadores diferentes tanto para a área de ADM quanto para a área de ECON. Observe também que, dentre os periódicos destacados na Tabela, a RBFIN é o periódico que apresenta maior paridade entre os números de pesquisadores relacionados a cada área, o que confirma a interdisciplinariedade da área de Finanças. Esta paridade, porém, não existe quando observamos o resultado para periódicos específicos de cada área. O periódico $R e$ vista de Administração (FEA-USP), por exemplo, é uma revista da área de Administração e apresentou apenas 8 pesquisadores diferentes na área de Economia, enquanto a quantidade de pesquisadores na área de Administração de Empresas foi de 22.

Observando as avaliações Qualis dos periódicos, fica claro que existem divergências entre as áreas. Em casos mais extremos, os periódicos $R A E$ e $R A C$ possuem classificação $\mathrm{A} 2$ na área Administração e B4 na área de Economia enquanto a revista Pesquisa e Planejamento Econômico é B1 na Economia e B3 na Administração. Porém, quando verifica-se o conjunto de periódicos da Tabela, fica claro que a área de Economia é em geral mais rígida que a área da Administração para os periódicos apresentados, ou seja, a área de Economia costuma atribuir uma classificação inferior em relação à classificação atribuída para o mesmo periódico na área de Administração.

A diferença entre as classificações do Qualis também explica a quantidade de pesquisadores em cada área. É natural esperar que cada pesquisador procure publicar em periódicos que possuam uma classificação mais alta no Qualis de sua área, de forma a maximizar a pontuação individual e coletiva do seu programa de pós-graduação. Utilizando o caso da $R A E$, observa-se 20 pesquisadores diferentes na área de $\mathrm{ADM}$ onde a mesma é classificada como $\mathrm{A} 2$ e apenas 4 da área de Economia, a qual classifica a $R A E$ como B4.

É importante apontar que as publicações de Finanças no Brasil são majoritariamente em veículos nacionais. Porém, vale destacar a presença de periódicos internacionais na lista dos 25 periódicos da Tabela 5. Esta é uma informação nova que não foi apresentada no literatura anterior (Leal et al., 2003, 2013). Um ponto curioso nesta análise é a presença do periódico Physica-A, o qual está majoritariamente vinculado à área de Física. É 
provável que a sua boa classificação no Qualis esteja motivando os pesquisadores a submeterem seus artigos para o mesmo. Destaca-se também a presença do periódico Journal of Banking and Finance dentre os mais publicados (total de 25 publicações). Este é um periódico de alto impacto, classificado no primeiro quartil pela SCImago $(\mathrm{SJR})^{5}$.

\subsection{Os periódicos internacionais}

A publicação de artigos em periódicos internacionais é desejável a qualquer área da ciência como forma de promover e divulgar a produção científica nacional. Em função a importância deste tópico na análise dos periódicos, busca-se mensurar a quantidade e a qualidade das publicações internacionais dos pesquisadores em Finanças vinculados a instituições brasileiras.

O primeiro passo desta análise foi buscar uma lista de periódicos internacionais da área de Finanças. Tal lista foi obtida junto ao site do SCImago Journal \& Country Rank, o qual disponibiliza o ranking dos periódicos de acordo com o seu índice de citação SJR para cada área do conhecimento, incluindo Finanças (subject area: Economics, Econometrics and Finance; subject category: Finance) ${ }^{6}$ A partir disto, verificou-se a quantidade de artigos publicados pelos pesquisadores de Finanças no Brasil utilizando o número ISSN destes periódicos. ${ }^{7}$

A lista dos 25 principais periódicos de Finanças com base nas informações dos currículos Lattes é apresentada na Tabela 5. A primeira coluna da Tabela 5 mostra a classificação (ranking) do periódico em função do seu SJR, o qual é um índice de qualidade do periódico baseado no número de citações recebidas, em média, por um artigo publicado em cada periódico em relação aos demais periódicos. ${ }^{8}$ A terceira coluna da tabela mostra o quartil do periódico em termos de qualidade medida pelo SJR. As últimas

\footnotetext{
${ }^{5}$ Informação baseada no ranking fornecido pelo SCImago Journal \& Country Rank http://www. scimagojr.com/ (acessado em 05/03/2015)

${ }^{6}$ http://www . scimagojr. com/journalrank.php (acessado em 05/03/2015).

${ }^{7}$ Como uma nota metodológica vale destacar que os periódicos do SJR podem possuir dois ISSN, um para a versão online e outro para a versão print da revista, enquanto as publicações registradas no Lattes mostram apenas um ISSN. Ambos foram considerados para a tabulação dos resultados apontados aqui.

${ }^{8}$ Para mais detalhes, ver http://www.scimagojr.com/SCImagoJournalRank.pdf (acessado em 05/03/2015)
} 
duas colunas mostram o número de artigos publicados em cada periódico bem como o número de autores diferentes que publicaram os artigos. 
Tabela 6: Os 25 periódicos internacionais da área de Finanças com o maior número de publicações por pesquisadores brasileiros

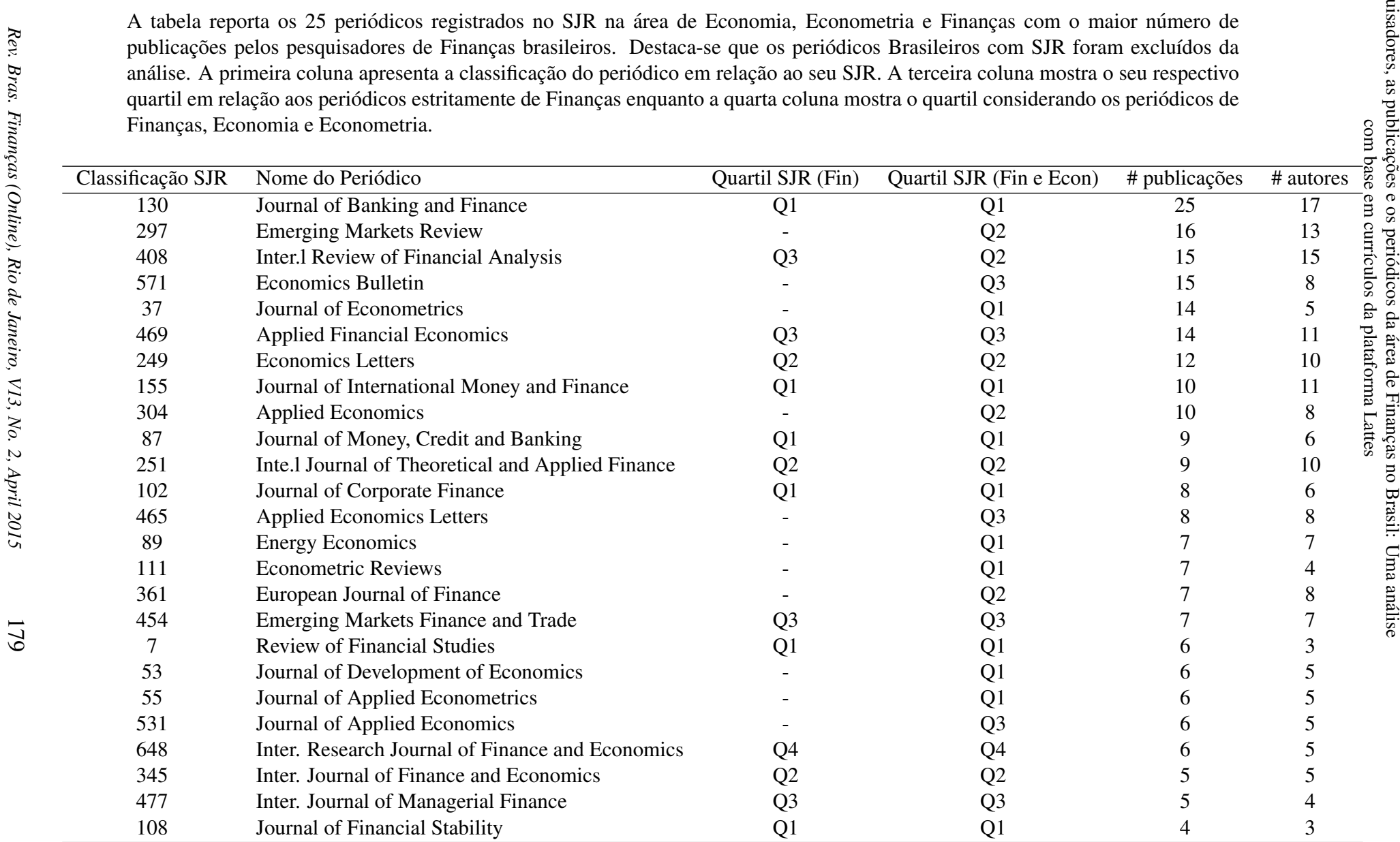


Conforme já foi visto na Tabela 5, o periódico Journal of Banking and Finance é o que apresenta o maior número de artigos publicados, com um total de 25. Observa-se também que os 25 artigos publicados neste periódico foram escritos por 17 autores, ou seja, os mesmos autores apareceram mais de uma vez nos diferentes artigos, o que indica certa concentração de pesquisadores neste periódico. Observando os periódicos do primeiro quartil (Q1) na terceira e quarta coluna da Tabela, destaca-se também as 10 publicações de 11 autores no periódico Journal of International Money and Finance, as 9 publicações de 6 autores no Journal of Money, Credit and Banking e as 8 publicações por 6 pesquisadores no Journal of Corporate Finance.

Observando-se o lado direito da distribuição em termos de SJR e JCR, isto é, os periódicos com maior impacto, verifica-se um trabalho publicado no prestigiado Journal of Finance obtido pelo professor Walter Novaes (Novaes (2002)). Salienta-se, porém, que se considerarmos artigos anteriores a 1990, encontramos outros dois autores brasileiros e três artigos neste mesmo periódico, conforme destacado por Leal et al. (2003): Walter L. Ness Jr (Cohen et al., 1976) e Ney Brito (Brito, 1977, 1978). Vale destacar também os 6 artigos publicados por pesquisadores brasileiros no igualmente prestigiado Review of Financial Studies.

A Figura 2 mostra a proporção de artigos publicados em função do quartil definido pelo SJR. A Figura considera os quartis segundo dois critérios de identificação de artigos: o primeiro (FIN) considera somente os artigos publicados em periódicos da área de Finanças enquanto que o segundo (FINECON), mais amplo, considera os artigos publicados em periódicos das áreas de Finanças, Economia e Econometria. Conforme pode ser visto, a maioria dos artigos internacionais está no primeiro quartil, com 79 publicações em periódicos da área de Finanças e 148 para a área mais geral de Economia, Econometria e Finanças. Isto mostra que a publicação internacional em periódicos registrados no SJR por pesquisadores brasileiros na área de Finanças, apesar de ainda ter uma participação pequena em relação ao total de publicações (16,35\%), é de alta qualidade, situada no primeiro e segundo quartil construído a partis dos respectivos SJRs dos periódicos. 
Figura 2: Número de publicações em função do Quantil SJR

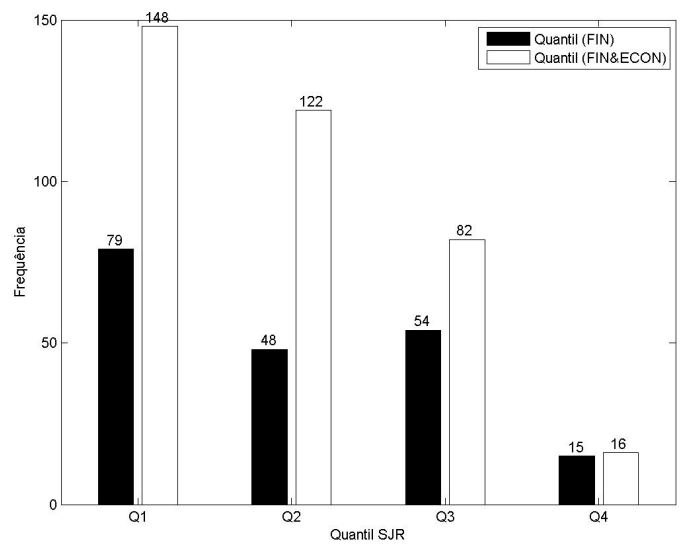

\subsection{Os artigos}

Esta seção analisa os artigos publicados pelos pesquisadores de Finanças no Brasil. Os dados obtidos através da plataforma Lattes incluem o ISSN do periódico, o título do artigo, os autores, o nome do periódico, a edição e volume, as páginas, o ano de publicação, o $J C R$ do periódico e o número de citações. Vale relembrar que apenar artigos publicados após 1990 e antes de 2015 foram considerados. No Lattes, as citações de cada artigo são registradas em três plataformas diferentes: Scopus, Scielo e Web of Science. É importante salientar que um artigo sem citação registrada no Lattes não indica necessariamente que o trabalho não foi usado como referência, mas sim que nenhuma citação foi registrada nas três plataformas citadas anteriormente.

Evitando-se priorizar uma plataforma ou outra, optou-se por selecionar para cada artigo o número máximo de citações encontrado nas três alternativas de forma a agregar os dados e simplificar a análise. Destaca-se também que as citações utilizadas nos cálculos foram calculadas pela divisão do número de citações máximo entre as plataformas, dividido pelo número de anos entre 2015 e o ano da publicação do artigo. Portanto, estamos analisando o número de citações por ano de cada artigo, o qual normaliza as citações do trabalho pelo tempo desde a sua publicação. Caso as citações não fossem ponderadas pelo tempo, teríamos um viés pois trabalho mais antigos tiveram maior oportunidade de atrair citações. 
Os principais tópicos de interesse nesta Seção são a quantidade e qualidade dos artigos publicados. Enquanto a primeira é fácil de quantificar, a segunda não o é pois a qualidade (ou impacto) de um artigo é difícil, se não impossível, de medir satisfatoriamente de forma totalmente objetiva e consensuada entre todos os pesquisadores. Conforme já foi destacado em tópico anterior, a classificação do Qualis foi utilizada para indicar a qualidade de grande maioria das publicações. Apesar de suas avaliações serem discutíveis (Da Silva, 2009, Guimaraes, 2012), o Qualis ainda é uma referência nas áreas o que justifica a sua utilização. Além disso, o Qualis também avalia os periódicos nacionais, muitos destes não contemplados nos sistemas internacionais de avaliação do tipo JCR ou SJR. Portanto, apesar de controversa, a tabela Qualis apresenta-se como a única forma "quasi-objetiva"de avaliar a qualidade dos periódicos nacionais. Porém, para publicações em periódicos indexados ao JCR, iremos analisar também os respectivos JCRs e as citações dos artigos.

Uma problemática no caso de utilizar o Qualis do periódico para avaliar a qualidade dos artigos é que cada área tem uma avaliação diferente. Conforme já foi visto na Tabela 5, o mesmo periódico pode ser $A 1$ em determinada área e $B 1$ em outra. Para o caso de uma área interdisciplinar tal como Finanças, a existência de dois Qualis deve ser levada em conta de modo que é desejável uma forma de agregação dessas avaliações. A solução utilizada nesta pesquisa foi dar prioridade para o Qualis mais restrito, o da área da Economia. Naqueles periódicos que não possuem Qualis na Economia e possuem Qualis na Administração, foi utilizado um simples método de mapeamento linear com base nas pontuações dos periódicos. Especificamente, primeiro elenca-se todos os periódicos que possuem Qualis na $\mathrm{ADM}$ e ECON e em seguida são construídos dois vetores, um com a correspondente pontuação na $\operatorname{ADM}\left(P Q_{i, A D M}\right)$ e outro com a pontuação na área de ECON $\left(P Q_{i, E C O N}\right){ }^{9}$ Após isto, estima-se uma regressão do tipo $P Q_{i, E C O N}=\alpha+\beta P Q_{i, A D M}+\epsilon_{i}$ por mínimos quadrados ordinários, obtendo-se então os parâmetros $\alpha$ e $\beta$. Com base nestes, calcula-se o Qualis esperado da Economia tendo como informação o Qualis da área de ADM. O Qualis correspondente da pontuação calculada é definido com base nos intervalos entre cada estrato. A Figura 3 a seguir apresenta a quantidade e qualidade dos artigos publicados.

No painel (a) da Figura 3 verifica-se a quantidade de publicações ao longo

\footnotetext{
${ }^{9} \mathrm{~A} 1=100, \mathrm{~A} 2=80, \mathrm{~B} 1=60, \mathrm{~B} 2=40, \mathrm{~B} 3=25, \mathrm{~B} 4=15, \mathrm{~B} 5=5$ e $\mathrm{C}=0$ 
dos anos. Observa-se um crescimento exponencial do número de trabalhos publicados ao longo do tempo, possivelmente em função da grande quantidade de novos pesquisadores (recém-doutores) a partir de 2005 (painel (b), Figura 1). No painel (b) da Figura 3 apresenta-se a quantidade de artigos em função do Qualis das áreas. Quando se utiliza os Qualis individuais para a área de Economia observa-se que a grande maioria dos artigos são B2 e B1, enquanto para a Administração a grande maioria pertence aos estratos A2 e B1. A coluna "Qualis ADM-ECON" representa o Qualis agregado utilizado no trabalho, levando em conta o mapeamento linear destacado anteriormente. Observa-se que a maior rigidez da área de Economia fica saliente nas frequências dos estratos, onde os estratos A1 e A2 possuem uma quantidade significativamente menor de publicações.

Figura 3: Estatísticas sobre publicações em Finanças no Brasil

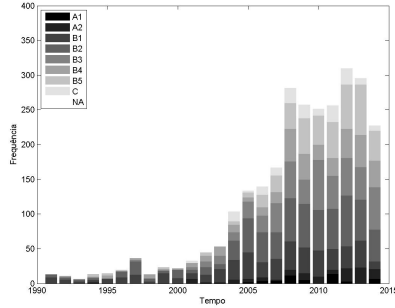

(5) Número de publicações por ano e segmentado por Qualis)

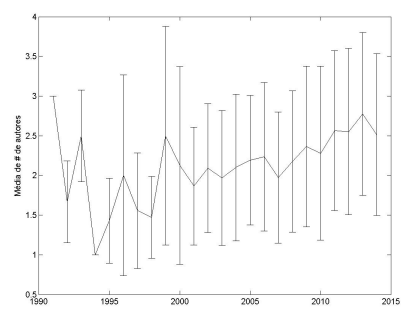

(7) Número de co-autores e erro padrão

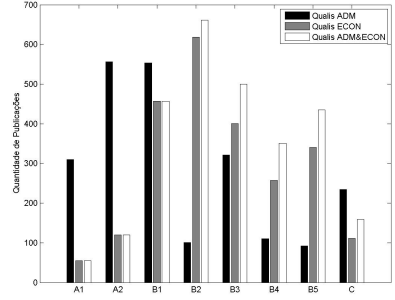

(6) Quantidade de publicações por Qualis ADM e ECON

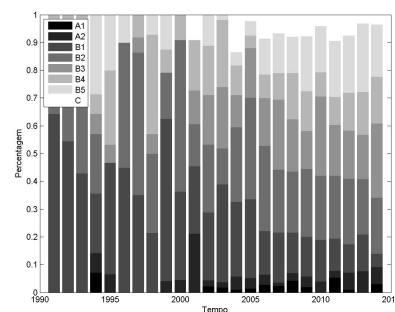

(8) \% de acordo com Qualis ADM e ECON

Ao analisar o número médio de autores por artigo em função dos anos, painel (c) da Figura 3, observa-se que a quantidade média de autores aumentou de aproximadamente 2,15 autores em 2000 para 2,5 em 2014. Este resultado também foi encontrado em Leal et al. (2013) e pode ser explicado pe- 
los benefícios para a contagem de pontos dos programas de pós-graduação pela CAPES, de forma a incentivar trabalhos com mais de um autor e entre instituições diferentes.

Por fim, o painel (d) da Figura 3 mostra a qualidade das publicações em Finanças ao longo do tempo medido pelo estrato do Qualis. A Figura indica que o número de publicações está crescendo porém isto não necessariamente indica um aumento da qualidade destas publicações. Se a qualidade das publicações se mantivesse constante, então a percentagem de cada estrato também deveria se manter fixa. Este porém, não é o padrão encontrado no painel (d). Observa-se que a partir de 2000 existe uma tendência da diminuição da participação de artigos em periódicos de alto e médio impacto (A1, A2 e B1) dentro do total de publicações, dando lugar para publicações em periódicos de baixo impacto (B2 até B5).

Outro ponto igualmente importante para este análise é compreender as tendências da publicações registradas em periódicos indexados ao JCR e SJR. Para a análise da publicações com fator de impacto e citações registradas no Lattes, apresenta-se a seguir Figura 4.

O painel (a) da Figura 4 mostra o número de publicações com JCR e citações registradas no Lattes para cada ano. Destaca-se uma clara tendência de aumento no número de publicações com JCR ao longo do tempo, enquanto o número de trabalhos com citações atinge um pico em 2008 e após isto vem decrescendo, o que pode ser explicado pelo fato de que um trabalho leva certo tempo até começar a ser referenciado, portanto aqueles artigos mais recentes tiveram menos oportunidade de serem citados. Vale ressaltar uma correlação positiva entre ambas métricas, a qual é justificada pois os periódicos com JCR geralmente possuem registro de citações em uma das plataformas (Scopus, Scielo e Web of Science). No painel (b) temos a percentagem de publicações com JCR e citações para cada ano. A média para cada uma ao longos dos anos foi de $16,14 \%$ e $14,12 \%$ respectivamente. Ou seja, de toda a produção científica pelos pesquisadores de Finanças do Brasil, uma pequena parcela foi publicada em periódicos registrados no JCR e outra menor parcela possui registro de citações.

O painel (c) da Figura 4 apresenta a média e a mediana dos JCRs da publicações para cada ano enquanto o painel (d) mostra a média e mediana dos número de citações. Os valores do JCR são bastante voláteis ao longo dos anos, possivelmente devido ao baixo número de observações. Reporta-se um JCR 
Figura 4: Estatísticas sobre publicações em periódico registrado no JCR

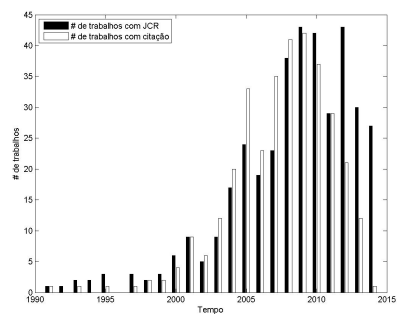

(9) \# de publicações com JCR e Citação

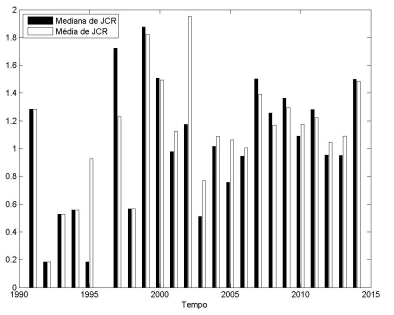

(11) Média e mediana do JCR do periódico

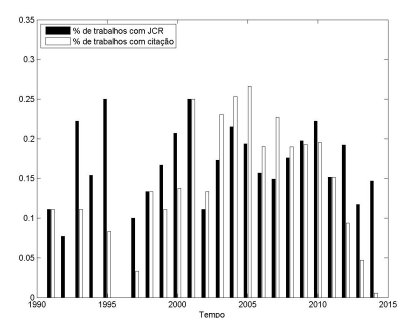

(10) Percentual de publicações com JCR e citações do total de publicações

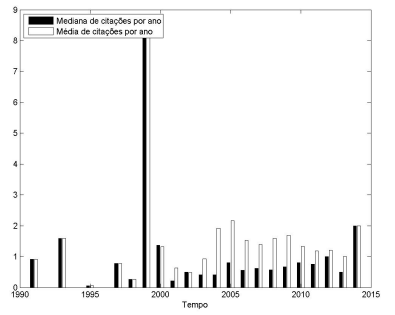

(12) Média e mediana de citações por ano

médio de 1,1 para a totalidade dos anos. Para o painel (d), no ano de 1999 observa-se um pico no número de citações. A averiguação dos dados mostra que neste período teve-se apenas dois artigos com JCR, ambos com um número alto de citações e de autoria do mesmo pesquisador. ${ }^{10} \mathrm{Na}$ média, porém, observamos que o número de citações por ano é de apenas 1,54, isto é, um novo artigo publicado em um periódico com JCR por pesquisadores de Finanças no Brasil tende a capturar 3 citações a cada dois anos.

Os resultados anteriores apresentam duas informações principais. Primeiro, a qualidade das publicações medido pelo Qualis tem diminuído ao longo do tempo. Segundo, são pouco volumosas as publicações em periódicos internacionais de impacto, quando medido pelo JCR e número de citações

\footnotetext{
${ }^{10}$ Os dois artigos são de co-autoria do Professor Ricardo Leal da UFRJ, Ratner \& Leal (1999) e Aggarwal et al. (1999) com respectivamente 59 e 213 como o máximo de citações entre Scopus, Scielo e Web of Science.
} 
registradas no Lattes. Duas hipóteses podem explicar o resultado anterior. A primeira é o argumento encontrado em Leal et al. (2013) de que os incentivos para a publicação em periódicos com alto impacto do ponto de vista de pontuação da CAPES são baixos. O argumento quantitativo é que o trabalho de uma publicação em periódico A1 (100 pontos) não equivale a duas publicações B2 $(50 * 2=100)$. Portanto, um pesquisador que busca maximizar a sua pontuação ao mesmo tempo que busca minimizar o trabalho necessário, irá inevitavelmente buscar periódicos de menor impacto, onde o rigor dos revisores é mais baixo e a publicação é mais provável. Dado que a grande maioria dos periódicos de alto impacto (localizados nos estratos A1 e A2) são internacionais, os incentivos para publicar nestes são baixos.

A segunda hipótese que também explicaria o declínio da qualidade das publicações é de que a nova entrada de recém doutores aumentou a quantidade dos artigos publicados, porém com um penalização na qualidade. Tal ocorrência seria justificada visto a falta de experiência dos novos profissionais e portanto não indicaria necessariamente um incentivo negativo para publicações em alto impacto, mas sim um efeito da entrada volumosa de novos pesquisadores. Estas e outras indagações são respondidas no tópico a seguir.

\section{A produtividade em Pesquisa}

A produtividade em pesquisa pode ser definida de diferentes maneiras. A forma mais simples de auferir a eficiência de um grupo de pesquisadores é analisar a quantidade de artigos publicados pelo conjunto em determinado período. Com este objetivo, apresentamos a seguir a Figura 5.

O painel (a) da Figura 5 mostra o número médio de publicações por autor. A visualização do gráfico mostra claramente um tendência positiva da produtividade dos pesquisadores em relação a quantidade de publicações, informação esta já parcialmente visualizada na Figura 3, painel (a). O painel (b), por sua vez, apresenta o número de periódicos diferentes para cada ano. Também está claro uma tendência positiva nestes valores, o que pode ser explicado pelo fato de que um maior número de autores tende a buscar uma maior diversidade nos periódicos para a publicação.

Outra possibilidade para avaliar a produtividade de pesquisadores em função 
Figura 5: Estatísticas sobre produtividade de autores

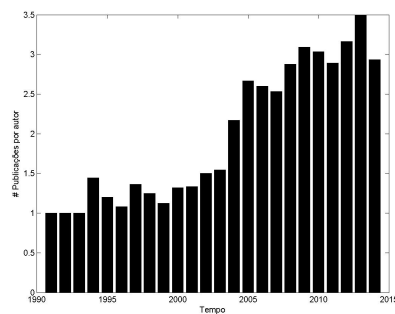

(13) Número de publicações por autor, por ano

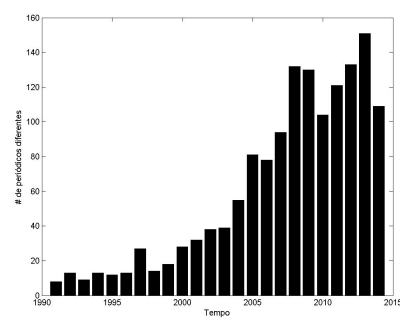

(14) Número de periódicos diferentes

da quantidade de publicações é o modelo de Lotka, o qual define uma expectativa matemática para a quantidade de publicações para cada autor com base em um modelo teórico de decaimento. Este procedimento foi adotado pela literatura anterior (Leal et al., 2003, 2013), onde é possível encontrar maiores detalhes técnicos sobre a sua implementação. $\mathrm{O}$ valor encontrado para o coeficiente de Lotka para os dados da pesquisa foi de 0,35 o qual é consideravelmente menor que o valor benchmark de 2 , sendo que valores maiores que este indicam uma menor produtividade dos autores. Portanto, os dados indicam que os pesquisadores possuem uma produtividade em termos de número maior do que o esperado. Este resultado é bastante contrastante ao valor de 2,63 obtido em Leal et al. (2013), porém pode ser explicado pela fato de que a base de dados utilizada na presente pesquisa é consideravelmente maior, incluindo um número considerável de novos periódicos e novas publicações, o que acaba impactando negativamente o valor do coeficiente de Lotka.

Vale salientar que a análise anterior sobre a produtividade dos pesquisadores levou em conta apenas a quantidade de artigos publicados. Quando utilizada isoladamente, tal inferência pode ser facilmente criticada pois a quantidade de publicações não indica necessariamente que as mesmas tiveram um impacto nas suas áreas de pesquisa. É preferencial, portanto, analisar também a qualidade das publicações dos pesquisadores. A metodologia utilizada para este fim foi agrupar os pesquisadores de acordo com diferentes critérios de produtividade e assim buscar entender melhor quais são os fatores comuns àqueles pesquisadores com maior e menor produtividade. Testes paramétricos (teste $t$ ) e testes não-paramétricos (teste de Wilcoxon) 
Perlin, M. S., Santos, A. P.

são utilizados para verificar se os atributos dos grupos são diferentes entre si. A seguir, na Tabela 7 apresentam-se os resultados. 
O primeiro painel da Tabela 7 divide os pesquisadores de acordo com a existência de pelo menos uma publicação em periódicos do estrato Q1 ou Q2 do SJR (Tabela 6, quarta coluna). O objetivo deste painel é verificar qual é o perfil dos pesquisadores que buscam publicar em periódicos internacionais de alto impacto. Na comparação contra o grupo de pesquisadores que nunca publicaram nos periódicos que atendem a esta classificação vemos que o primeiro grupo tem maior tempo desde o doutorado, com uma média de ano igual a 2004,08 contra uma média de 2005,89 para o segundo grupo, o que pode ser explicado pela experiência profissional necessária para produzir artigos internacionais. Uma diferença significativa também é encontrada para o total de pontos Qualis e a média de pontos Qualis por artigo publicado, o que é de certa forma esperado em função da forma como os grupos foram montados. É interessante notar também que o primeiro grupo possui um número de artigos publicados estatisticamente maior do que o segundo grupo, isto é, os autores que publicam em periódicos do estrato Q1 ou Q2 do SJR tendem a ser também aqueles que possuem um maior número de publicações.

Um ponto muito interessante no painel A da Tabela 7 é o fato de que a proporção de pesquisadores com doutorado fora do país é significativamente maior em comparação com o segundo grupo. Isto é, dentro do grupo de pesquisadores com artigos publicados em periódicos internacionais de alto impacto, $47,1 \%$ destes realizaram seus estudos de doutorado em uma instituição internacional. Este resultado pode ser explicado pela facilidade dos pesquisadores com doutorado fora do país em escrever em língua inglesa e também pela qualidade da formação em uma instituição internacional, formando portanto pesquisadores mais propícios a obter publicações internacionais de impacto. Verifica-se também um resultado significativo para a proporção de pesquisadores com bolsa de produtividade do CNPQ, o que é um resultado esperado visto que a bolsa é um incentivo financeiro para o pesquisador, resultado de uma avaliação das suas publicações e também de outros critérios. Observa-se que este grupo de pesquisadores apresenta uma média de $27,4 \%$ de suas publicações em periódicos indexados ao JCR.

O segundo painel da Tabela 7 foi construído utilizando o número total de publicações como critério de produtividade. É Importante notar que esta foi a medida utilizada em Leal et al. (2013) para definir pesquisadores produtivos, mais especificamente, aqueles pesquisadores com mais de 5 
Tabela 7: Comparação entre grupos de pesquisadores segundo publicação em periódico do SJR, maior número de publicações e maior pontuação média por publicação

A tabela reporta as características de diferentes grupos de pesquisadores, os quais foram agrupados de acordo com três diferentes métricas de produtividade em pesquisa: existência de publicações no primeiro e segundo quantil do SJR, número de publicações e a pontuação Qualis média por artigo. Após o agrupamento dos pesquisadores, diversas estatísticas agregadas são computadas e verifica-se se existe uma diferença significativa para a média e a mediana destes fatores tal como o ano de doutoramento, número de publicações e diversos outros. Para a análise das proporções, por exemplo o percentual de pesquisadores com bolsa de produtividade, utilizou-se um teste de diferença de proporções, sob a hipótese nula de que as proporções são iguais. Os símbolos *, ** $\mathrm{e}^{* * *}$ indicam significância estatística a $10 \%$, $5 \%$ e $1 \%$, respectivamente.

\begin{tabular}{|c|c|c|c|c|}
\hline \multicolumn{5}{|c|}{ Painel A: Grupos definidos por publicação em quantil Q1 ou Q2 do SJR (Fin \& Econ) } \\
\hline & Grupo 1 & Grupo 2 & Teste $\mathrm{T}$ & Teste Wilcoxon (ranksum) \\
\hline Número de Pesquisadores & 70 & 104 & & \\
\hline Média do ano de término do doutorado & 2004,086 & 2005,894 & $-1,551$ & $-2,195 * *$ \\
\hline Média de número de publicações & 26,443 & 15,529 & $2,657 * * *$ & $4,236 * * *$ \\
\hline Média do total de pontos Qualis & 1098,973 & 381,487 & $4,634 * * *$ & $5,744 * * *$ \\
\hline Média de pontos Qualis por artigo & 53,313 & 33,351 & $8,894 * * *$ & $7,397 * * *$ \\
\hline Média de números de co-autores & 2,461 & 2,584 & $-1,123$ & $-1,993 * *$ \\
\hline Média de fator de impacto dos periódicos (JCR) & 0,933 & 0,113 & $9,881 * * *$ & $7,907 * * *$ \\
\hline Média de citações por ano desde publicação & 0,877 & 0,080 & $4,099 * * *$ & $6,496 * * *$ \\
\hline Média de $\%$ de trabalhos em JCR & 0,274 & 0,039 & $8,104 * * *$ & $7,459 * * *$ \\
\hline$\%$ de pesquisadores com bolsa produtividade & $0,286^{*}$ & 0,038 & & \\
\hline$\%$ de pesquisadores com doutorado fora do Brasil & $0,471 * * *$ & 0,106 & & \\
\hline$\%$ de pesquisadores com pós-doutorado & 0,229 & 0,144 & & \\
\hline$\%$ de pesquisadores com publicações em SJR & 1,000 & 0,000 & & \\
\hline \multicolumn{5}{|c|}{ Painel B: Grupos definidos pelo número total de publicações (maior que o $3^{\circ}$ quartil) } \\
\hline & Grupo 1 & Grupo 2 & Teste $\mathrm{T}$ & Teste Wilcoxon (ranksum) \\
\hline Número de Pesquisadores & 44 & 130 & & \\
\hline Média do ano de término do doutorado & 2000,114 & 2006,877 & $-5,543^{* * *}$ & $-5,595^{* * *}$ \\
\hline Média de número de publicações & 54,295 & 8,285 & $14,513 * * *$ & $9,912 * * *$ \\
\hline Média do total de pontos Qualis & 1921,800 & 246,489 & $12,486^{* * *}$ & $9,500 * * *$ \\
\hline Média de pontos Qualis por artigo & 43,705 & 40,907 & 0,919 & 1,110 \\
\hline Média de números de co-autores & 2,552 & 2,528 & 0,187 & $-0,071$ \\
\hline Média de fator de impacto dos periódicos (JCR) & 0,602 & 0,389 & $1,837 *$ & $3,841 * * *$ \\
\hline Média de citações por ano desde publicação & 0,678 & 0,307 & 1,630 & $6,335 * * *$ \\
\hline Média de $\%$ de trabalhos em JCR & 0,180 & 0,119 & 1,593 & $3,833 * * *$ \\
\hline$\%$ de pesquisadores com bolsa produtividade & $0,409 * *$ & 0,046 & & \\
\hline$\%$ de pesquisadores com doutorado fora do Brasil & 0,318 & 0,231 & & \\
\hline$\%$ de pesquisadores com pós-doutorado & 0,273 & 0,146 & & \\
\hline$\%$ de pesquisadores com publicações em SJR & $0,568 * *$ & 0,346 & & \\
\hline \multicolumn{5}{|c|}{ Painel C: Grupos definidos pela maior pontuação Qualis por artigo (maior que o $3^{\circ}$ quartil) } \\
\hline & Grupo 1 & Grupo 2 & Teste $\mathrm{T}$ & Teste Wilcoxon (ranksum) \\
\hline Número de Pesquisadores & 47 & 127 & & \\
\hline Média do ano de término do doutorado & 2004,021 & 2005,591 & $-1,215$ & $-1,435$ \\
\hline Média de número de publicações & 24,617 & 18,181 & 1,398 & 1,281 \\
\hline Média do total de pontos Qualis & 1179,522 & 481,616 & $4,026 * * *$ & $3,476^{* * *}$ \\
\hline Média de pontos Qualis por artigo & 61,610 & 33,765 & $13,574 * * *$ & $10,022 * * *$ \\
\hline Méd1ate números RevoBaxusresinanças (Online), & $R \not, 3 \& \varrho J a$ & leiß,59113, & $N o-1272$ 2hpril & $-2 @(1)$ \\
\hline Média de fator de impacto dos periódicos (JCR) & 0,800 & 0,311 & $4,513 * * *$ & $3,627 * * *$ \\
\hline Média de citações por ano desde publicação & 0,680 & 0,297 & $1,718 *$ & $3,690 * * *$ \\
\hline Média de $\%$ de trabalhos em JCR & 0,289 & 0,077 & $6,242 * * *$ & $4,117 * * *$ \\
\hline$\%$ de pesquisadores com bolsa produtividade & $0,277^{*}$ & 0,087 & & \\
\hline$\%$ de pesquisadores com doutorado fora do Brasil & $0,447 * *$ & 0,181 & & \\
\hline$\%$ de pesquisadores com pós-doutorado & 0,191 & 0,173 & & \\
\hline$\%$ de pesquisadores com publicações em SJR & $0,766^{* * *}$ & 0,268 & & \\
\hline \multicolumn{5}{|c|}{ Painel D: Grupos definidos pela menor pontuação Qualis por artigo (menor que o $1^{\circ}$ quartil) } \\
\hline & Grupo 1 & Grupo 2 & Teste $\mathrm{T}$ & Teste Wilcoxon (ranksum) \\
\hline Número de Pesquisadores & 43 & 131 & & \\
\hline Média do ano de término do doutorado & 2007,326 & 2004,458 & $2,178 * *$ & $1,685^{*}$ \\
\hline Média de número de publicações & 14,163 & 21,809 & $-1,617$ & $-3,790 * * *$ \\
\hline Média do total de pontos Qualis & 217,328 & 818,761 & $-3,323 * * *$ & $-6,671 * * *$ \\
\hline Média de pontos Qualis por artigo & 17,710 & 48,044 & $-13,189 * * *$ & $-9,062 * * *$ \\
\hline Média de números de co-autores & 2,606 & 2,511 & 0,745 & 1,497 \\
\hline Média de fator de impacto dos periódicos (JCR) & 0,090 & 0,559 & $-4,164 * * *$ & $-4,531 * * *$ \\
\hline Média de citações por ano desde publicação & 0,049 & 0,516 & $-2,040 * *$ & $-3,863 * * *$ \\
\hline Média de \% de trabalhos em JCR & 0,015 & 0,173 & $-4,238 * * *$ & $-4,667 * * *$ \\
\hline$\%$ de pesquisadores com bolsa produtividade & 0,023 & 0,176 & & \\
\hline$\%$ de pesquisadores com doutorado fora do Brasil & 0,140 & 0,290 & & \\
\hline$\%$ de pesquisadores com pós-doutorado & 0,140 & 0,191 & & \\
\hline$\%$ de pesquisadores com publicações em SJR & $0,070^{*}$ & 0,511 & & \\
\hline
\end{tabular}


publicações. Para o caso deste artigo, optou-se por utilizar o terceiro quartil da distribuição do número de publicações como ponto de corte para separar os grupos (no caso, 25 publicações). Observa-se que os resultados do painel B são semelhantes aos do painel A, onde os pesquisadores são mais antigos em relação ao ano do doutorado, com proporções significativas de percentual de pesquisadores com bolsa de produtividade e publicações em periódicos indexados ao SJR. Salienta-se, porém, que o maior número de publicações não indica necessariamente uma decaída na pontuação média por artigo. De fato, os testes mostram que não existem diferenças significativas da pontuação média por artigo entre um grupo e outro. Ao analisar a média do fator de impacto (JCR) para o primeiro grupo vemos que a mesma é maior em relação ao valor encontrado para o segundo grupo e esta diferença é significativa.

O terceiro painel encontrado na Tabela 7 mostra os resultados para o caso de dividir os grupos de pesquisadores de acordo com a média de pontuação Qualis por publicação. Utilizou-se novamente o terceiro quartil (50,85 pontos médios por artigo) como ponto de corte. Os pesquisadores do primeiro grupo são aqueles que possuem a maior pontuação média por artigo publicado, isto é, levando o Qualis em conta, os mesmos privilegiam qualidade em vez de quantidade. É importante notar que a data média de término do doutorado não é significativamente diferente entre os dois grupos.

Porém, quando olhamos o outro lado da distribuição, isto é, o perfil daqueles pesquisadores com a menor média de pontos qualis por publicação, não encontramos o mesmo resultado. No Painel D da Tabela 7 os pesquisadores foram divididos pela menor pontuação por artigo ( $1^{\circ}$ quartil, 17,71 pontos médios por artigo). Os resultados mostram que este grupo que possui as menores pontuações médias tem ano de doutorado maior do que os demais. Portanto, uma possível explicação para a deterioração da qualidade dos artigos visualizada na Figura 3 é a entrada de novos pesquisadores. É curioso, porém, identificar que dentro deste grupo existe um pesquisadores $(2,3 \%)$ com bolsa de produtividade. Uma verificação dos dados mostra porém que tal pesquisador é de outra área que não $\mathrm{ADM}$ ou ECON, indicando que se fosse utilizado outro Qualis, possivelmente este teria um alto valor de pontos por publicações.

Partimos agora para a análise dos fatores de produtividade levando em conta aspectos de periódicos indexados, o JCR e o número de citações por ano de cada pesquisador. Na Tabela 8 , utilizamos o mesmo procedimento de 
diferenciação de grupos com base na seleção dos pesquisadores com valores de JCR médio, número médio de citações por ano e proporção de publicações em JCR maior do que os seus respectivos $3^{\circ}$ quartis.

Os grupos formados por ambos os critérios podem ser entendidos como a elite da produtividade científica em Finanças no Brasil. Os valores na Tabela 8 mostram que estes pesquisadores possuem JCR médio, número de citações por ano, média de proporção de trabalhos com JCR, média de pontos Qualis por artigo consideravelmente maior do que a média do outro grupo, o que é facilmente identificado pelas estatísticas de comparação de médias e medianas. Nesta tabela, painéis $\mathrm{A}, \mathrm{B}$ e $\mathrm{C}$, fica novamente claro o papel do doutorado fora do país, onde $52,6 \%, 56,3 \%$ e $47,4 \%$ dos pesquisadores possuem doutorado em instituição estrangeira. Também é possível enxergar uma correlação positiva entre qualidade e quantidade, isto é, aqueles pesquisadores com maior inserção em periódicos de impacto e com maior número de citações por ano, são também aqueles com um número maior de publicações. Este resultado também é encontrado para o painel C, porém o teste utilizado mostra que a diferença do número de publicações entre um grupo e outro não é significativa.

Uma informação interessante da Tabela 8 é com relação a proporção de bolsistas de produtividade, o qual oscila em torno de $50 \%$ para os três diferentes painéis. Dado que estes são os pesquisadores com os maiores impactos científicos internacionais medido pelo JCR médio e número de citações médio, seria esperado que todos possuíssem a bolsa de produtividade. O fato de que apenas aproximadamente metade possui a bolsa de produtividade mostra um possível desvio em relação ao impacto internacional das avaliações do CNPQ ou um desinteresse neste recurso por parte dos pesquisadores.

\section{Recomendações de políticas e ações para fomentar a pesquisa em Finanças realizada no Brasil}

Os resultados encontrados nesta pesquisa sugerem algumas linhas de ações que podem fomentar não apenas a quantidade mas principalmente a qualidade da pesquisa em Finanças realizada no Brasil:

1. Fomento ao doutoramento em instituições de referência fora do país: Os resultados apontados nas Tabelas 7 e 8 indicam claramente 
Tabela 8: Comparação entre grupos de pesquisadores segundo JCR e citações por ano

A tabela reporta as características de diferentes grupos de pesquisadores, os quais foram agrupados de acordo com três diferentes métricas de produtividade em pesquisa para periódicos indexados: valor médio do JCR, número de citações por ano e proporção de publicações em JCR. Conforme descrito na tabela 7, após o agrupamento dos pesquisadores diversas estatísticas agregadas são computadas e verifica-se se existe uma diferença significativa para a média e a mediana destes fatores entre os diferentes grupos. Os símbolos *, $* * \mathrm{e} * * *$ indicam significância estatística a $10 \%, 5 \%$ e $1 \%$, respectivamente.

\begin{tabular}{|c|c|c|c|c|}
\hline \multicolumn{5}{|c|}{ Painel A: Grupos definidos pela média de JCR das publicação (maior que o $3^{\circ}$ quartil) } \\
\hline & Grupo 1 & Grupo 2 & Teste $\mathrm{T}$ & Teste Wilcoxon (ranksum) \\
\hline Número de Pesquisadores & 19 & 155 & & \\
\hline Média do ano de término do doutorado & 2004,105 & 2005,297 & $-0,646$ & $-1,097$ \\
\hline Média de número de publicações & 30,632 & 18,606 & $1,843^{*}$ & 1,527 \\
\hline Média do total de pontos Qualis & 1409,873 & 579,453 & $3,318^{* * *}$ & $2,512 * *$ \\
\hline Média de pontos Qualis por artigo & 62,910 & 38,900 & $6,332^{* * * *}$ & $5,392 * * *$ \\
\hline Média de números de co-autores & 2,609 & 2,525 & 0,485 & $-0,085$ \\
\hline Média de fator de impacto dos periódicos (JCR) & 1,656 & 0,294 & $10,805^{* * *}$ & $7,099 * * *$ \\
\hline Média de citações por ano desde publicação & 2,100 & 0,192 & $6,689 * * *$ & $5,290 * * *$ \\
\hline Média de \% de trabalhos em JCR & 0,638 & 0,072 & $17,924 * * *$ & $7,638^{* * *}$ \\
\hline \% de pesquisadores com bolsa produtividade & $0,368 * *$ & 0,110 & & \\
\hline$\%$ de pesquisadores com doutorado fora do Brasil & $0,526 * *$ & 0,219 & & \\
\hline \% de pesquisadores com pós-doutorado & 0,263 & 0,168 & & \\
\hline$\%$ de pesquisadores com publicações em SJR & $0,895^{* * *}$ & 0,342 & & \\
\hline \multicolumn{5}{|c|}{ Painel B: Grupos definidos pela média de citações por ano (maior que o $3^{\circ}$ quantil) } \\
\hline & Grupo 1 & Grupo 2 & Teste T & Teste Wilcoxon (ranksum) \\
\hline Número de Pesquisadores & 16 & 158 & & \\
\hline Média do ano de término do doutorado & 2000,375 & 2005,652 & $-2,704 * * *$ & $-3,415^{* * *}$ \\
\hline Média de número de publicações & 48,313 & 17,044 & 4,666 **** & $3,592 * * *$ \\
\hline Média do total de pontos Qualis & 2184,983 & 516,728 & $6,728^{* * * *}$ & $3,732 * * *$ \\
\hline Média de pontos Qualis por artigo & 62,621 & 39,411 & $5,542 * * *$ & $4,747 * * *$ \\
\hline Média de números de co-autores & 2,459 & 2,542 & $-0,445$ & $-0,723$ \\
\hline Média de fator de impacto dos periódicos (JCR) & 1,599 & 0,326 & $8,657^{* * * *}$ & $6,243 * * *$ \\
\hline Média de citações por ano desde publicação & 2,762 & 0,161 & $9,188^{* * *}$ & $7,386^{* * *}$ \\
\hline Média de $\%$ de trabalhos em JCR & 0,563 & 0,091 & $10,461 * * *$ & $6,514 * * *$ \\
\hline$\%$ de pesquisadores com bolsa produtividade & $0,500 * * *$ & 0,101 & & \\
\hline$\%$ de pesquisadores com doutorado fora do Brasil & $0,563 * *$ & 0,222 & & \\
\hline \% de pesquisadores com pós-doutorado & 0,313 & 0,165 & & \\
\hline$\%$ de pesquisadores com publicações em SJR & $0,938 * * *$ & 0,348 & & \\
\hline \multicolumn{5}{|c|}{ Painel C: Grupos definidos pelo percentual de publicações com JCR (maior que o $3^{\circ}$ quantil) } \\
\hline & Grupo 1 & Grupo 2 & Teste $\mathrm{T}$ & Teste Wilcoxon (ranksum) \\
\hline Número de Pesquisadores & 19 & 155 & & \\
\hline Média do ano de término do doutorado & 2003,842 & 2005,329 & $-0,807$ & $-1,353$ \\
\hline Média de número de publicações & 28,053 & 18,923 & 1,393 & 1,147 \\
\hline Média do total de pontos Qualis & 1304,966 & 592,312 & $2,823 * * *$ & $2,391^{* *}$ \\
\hline Média de pontos Qualis por artigo & 63,069 & 38,880 & $6,391 * * *$ & $5,382 * * *$ \\
\hline Média de números de co-autores & 2,470 & 2,542 & $-0,418$ & $-0,763$ \\
\hline Média de fator de impacto dos periódicos (JCR) & 1,499 & 0,313 & $8,718^{* * * *}$ & $6,586^{* * *}$ \\
\hline Média de citações por ano desde publicação & 1,934 & 0,213 & $5,893 * * *$ & $4,120 * * *$ \\
\hline Média de $\%$ de trabalhos em JCR & 0,654 & 0,070 & 19,760 **** & $7,773 * * *$ \\
\hline$\%$ de pesquisadores com bolsa produtividade & $0,368 * *$ & 0,110 & & \\
\hline$\%$ de pesquisadores com doutorado fora do Brasil & $0,474^{*}$ & 0,226 & & \\
\hline$\%$ de pesquisadores com pós-doutorado & 0,263 & 0,168 & & \\
\hline$\%$ de pesquisadores com publicações em SJR & $0,947 * * *$ & 0,335 & & \\
\hline
\end{tabular}


que pesquisadores que realizaram estudos em nível de doutorado fora do país possuem não apenas maior produtividade em pesquisa como também produzem artigos publicados em periódicos de maior impacto, indexados ao JCR e SJR. Isso sugere que a formação obtida em instituições estrangeiras com tradição em Finanças tem, de fato, um impacto em termos da qualidade das publicações e da produtividade do pesquisador em atuação no território nacional. Portanto, o fomento à realização do doutoramento em instituições de referência fora do país é uma recomendação benéfica para a pesquisa em Finanças realizada no Brasil. Vale notar que a realização do doutoramento fora do país está geralmente condicionada à concessão de financiamento por parte de agências de fomento como, por exemplo, CAPES e CNPQ. Entretanto, no que diz respeito à área de Finanças, é comum observar que instituições de referência possuem fontes próprias de financiamento, o que amplia em muito o rol de possibilidades por parte dos candidatos. Além de fomentar a pesquisa realizada no território nacional, o retorno de parte desses pesquisadores ao país gera um efeito positivo também para a formação de novas gerações de pesquisadores. Também vale pontuar outras vantagens em se realizar o doutorado em instituição estrangeira como, por exemplo, (1) fazer parte de uma rede de pesquisadores internacionais situados em boas escolas, contando, por exemplo, com seu orientador de doutorado, outros professores e colegas de programa; (2) acesso a bancos de dados de alto custo, com informações que facilitam a publicação em revistas internacionais, em contraste ao acesso a banco de dados circunscritos ao Brasil, como é o caso da maioria das instituições brasileiras; (3) treinamento, durante o programa, para escrever artigos de alto impacto, com participação frequente em seminários que contam com a participação de pesquisadores influentes em suas áreas.

2. Fomento à retribuição financeira: Outra característica observada a partir dos resultados da Tabela 7 é a incidência de pesquisadores com bolsa de produtividade dentre aqueles com maior número e também maior qualidade de publicações. Isso sugere que a recompensa financeira pode atuar como um estímulo à realização de pesquisas com maior impacto e, consequentemente, maior potencial de publicação em periódicos de primeira linha. 
3. Alinhamento de incentivos: A qualidade, medida em termos de impacto científico, das pesquisas em Finanças, assim como em qualquer outra área, é uma função direta dos incentivos que estão postos aos seus pesquisadores. Um desses incentivos é justamente a pontuação que diversos periódicos (nacionais e internacionais) possuem no Qualis, que é atualmente a principal fonte de referência para contagem de pontos na grande maioria dos programas de pósgraduação do país. Obviamente, está fora do escopo deste artigo avaliar se este ou aquele periódico está corretamente avaliado dentro da plataforma. Entretanto, é importante frisar que todo pesquisador almeja maximizar o número de pontos das suas publicações dado o nível de esforço dispendido para tal. Sendo assim, um pesquisador que almeje atingir 100 pontos pode fazê-lo de várias formas: 1 artigo publicado em periódico classificado no estrado A1 ou, por exemplo, 4 artigos publicados em periódicos classificados no estrato B3. Pode-se argumentar, entretanto, que o impacto das 4 publicações em periódicos B3 não é equivalente ao impacto de 1 publicação em um periódico A1. Isso pode gerar um incentivo perverso ao estimular realização de um maior número de pesquisas que serão posteriormente publicadas em periódicos de baixo impacto científico. Dessa forma, usando o mesmo argumento de Leal et al. (2013), sugerese uma revisão e aprimoramento da pontuação atribuída aos diferentes estratos de modo a incrementar o incentivo a publicar em periódicos situados nos estratos mais altos. Esta nova classificação para periódicos de alta qualidade deve levar em conta avaliações internacionais já existentes (SJR, JCR) para definir os estratos superiores.

\section{Conclusões}

O objetivo deste trabalho foi apresentar uma análise do perfil da pesquisa em Finanças no Brasil tendo como base de dados a plataforma de currículos Lattes. Na primeira etapa, após a identificação dos pesquisadores em Finanças, foi construído uma análise do perfil dos pesquisadores, seguida pela análise dos periódicos nacionais e internacionais, terminando com um estudo da quantidade e qualidade das publicações dos pesquisadores nacionais. Além disto, buscou-se também realizar uma investigação dos fatores da produtividade dos pesquisadores, sendo esta inédita na literatura. 
A primeira parte da pesquisa apresentou a divisão do número de pesquisadores entre as diferentes áreas, ressaltando a interdisciplinaridade da área de Finanças. Mostra-se também que o número de doutores em Finanças está crescendo de forma exponencial, onde a maioria dos pesquisadores terminaram o doutorado após 2005. Espera-se que estes novos doutores orientem novos alunos, indicando uma tendência positiva para o aumento do número de pesquisadores em Finanças no Brasil. Além disso, apresentamos novas evidências da aglomeração geográfica de pesquisadores, especialmente em São Paulo, Rio de Janeiro e Brasília.

A análise dos periódicos mostrou, tendo como base o número de publicações dos pesquisadores, a RBFIN como a principal revista de Finanças do Brasil, seguida pela $R B E$ e a $R A$ (FEA-USP). Para os periódicos internacionais de impacto, mostrou-se que a participação dos mesmos é pequena $(16,35 \%)$ em termos relativos ao total de publicações registradas. Porém, quando analisando a qualidade destas publicações em periódicos indexados ao SJR, verificamos que o grande percentual está situado no primeiro e segundo quantil em termos de valores de SJR.

No estudo sobre as publicações mostrou-se uma tendência no aumento do número de autores por artigo e também um crescimento exponencial no número de artigos publicados ao longo dos anos, a qual é confirmada através da aplicação do modelo de Lotka. A pesquisa mostra, porém, que a qualidade dos artigos tem diminuído. Análise mais aprofundada dos dados permitiu identificar que esta queda de qualidade pode ser explicada pela entrada de novos pesquisadores.

Por fim, é importante ressaltar que este artigo tem uma natureza quantitativa. Investigações futuras poderiam empregar uma abordagem qualitativa. Por exemplo, pode-se identificar e entrevistar os autores que atuam no Brasil dos artigos de finanças publicados nos periódicos de maior fator de impacto listados na Tabela 5. As entrevistas poderiam ser estruturadas e abordar temas como suas motivações para buscar periódicos de maior rigor, impressões sobre o critério de avaliação de periódicos empregado pelo Qualis de sua área e percepções a respeito da qualidade da pesquisa em finanças realizada no Brasil e as motivações dos pesquisadores que atuam no Brasil de forma geral. A análise qualitativa sobre o que pensam os pesquisadores que atuam no Brasil com maior impacto internacional pode ser reveladora de aspectos que não são facilmente realçados por investigações quantitativas, com potencial de oferecer subsídios para uma avaliação do impacto 
Os pesquisadores, as publicações e os periódicos da área de Finanças no Brasil: Uma análise com base em currículos da plataforma Lattes

dos critérios de classificação de periódicos usados no Brasil. 


\section{Referências}

Aggarwal, Reena, Inclan, Carla, \& Leal, Ricardo. 1999. Volatility in emerging stock markets. Journal of Financial and Quantitative Analysis, 34(01), 33-55.

Alexander, John C, \& Mabry, Rodney H. 1994. Relative significance of journals, authors, and articles cited in financial research. The Journal of Finance, 49(2), $697-712$.

Brito, Ney O. 1977. Marketability restrictions and the valuation of capital assets under uncertainty. The Journal of finance, 32(4), 1109-1123.

Brito, Ney O. 1978. Portfolio selection in an economy with marketability and short sales restrictions. The Journal of Finance, 33(2), 589-601.

Camargos, Marcos Antônio de, Coutinho, Eduardo Senra, \& Amaral, Hudson Fernandes. 2005. O perfil da área de finanças do EnANPAD: um levantamento da produção científica e de suas tendências entre 2000-2004. Anais do Encontro Nacional da Associação Nacional de Pós-Graduação e Pesquisa em Administração.

Camargos, Marcos Antônio de, Silva, Wendel Alex Castro, \& Dias, Alexandre Teixeira. 2009. Análise da produção científica em finanças entre 2000-2008: um estudo bibliométrico dos encontros da ANPAD. Encontro da Associação Nacional de Pós-Graduação e Pesquisa em Administração, 33.

Chen, Carl R, \& Huang, Ying. 2007. Author Affiliation Index, finance journal ranking, and the pattern of authorship. Journal of Corporate Finance, 13(5), 1008-1026.

Chung, Kee H, \& Cox, Raymond AK. 1990. Patterns of productivity in the finance literature: a study of the bibliometric distributions. the Journal of Finance, 45(1), 301-309.

Chung, Kee H, Cox, Raymond AK, \& Mitchell, John B. 2001. Citation patterns in the finance literature. Financial Management, 99-118.

Cohen, Kalman J, Ness, Walter L, Okuda, Hitoshi, Schwartz, Robert A, \& Whitcomb, David K. 1976. The determinants of common stock returns volatility: An international comparison. The Journal of Finance, 31(2), 733-740.

Cordeiro, Rebeca Albuquerque, Sanches, Paula Luciana Bruschi, de Oliveira Cavalcante, Keliane, Peixoto, Amanna Ferreira, \& de Lacerda Leite, José Carlos. 2014. Pesquisa Quantitativa em Finanças: Uma Análise das Técnicas Estatísticas Utilizadas por Artigos Científicos Publicados em Periódicos Qualificados no Triênio 2007-2009. Revista de Administração da UFSM, 7(1), 117-134. 
Currie, Russell R, \& Pandher, Gurupdesh S. 2011. Finance journal rankings and tiers: An Active Scholar Assessment methodology. Journal of Banking \& Finance, 35(1), 7-20.

Da Silva, Sergio. 2009. Going parochial in the assessment of the Brazilian economics research output. Economics Bulletin, 29(4), 2826-2846.

Guimaraes, Bernardo. 2012. Qualis as a measuring stick for research output in Economics. Brazilian Review of Econometrics, 31(1), 03-18.

Lane, Julia. 2010. Let's make science metrics more scientific. Nature, 464(7288), 488-489.

Leal, Ricardo Pereira Câmara, Oliveira, Jefferson, \& Soluri, Aline Feldman. 2003. Perfil da pesquisa em finanças no Brasil. Revista de Administração de Empresas, 43(1), 1-14.

Leal, Ricardo Pereira Câmara, Almeida, Vinicio de Souza, \& Bortolon, Patrícia Maria. 2013. Produção científica brasileira em finanças no período 2000-2010. RAE - Revista de Administração de Empresas, 53.

Lotka, Alfred James. 1926. The frequency distribution of scientific productivity. Journal of Washington Academy Sciences.

Mabry, Rodney H, \& Sharplin, Arthur D. 1985. The relative importance of journals used in finance research. Journal of Financial Research, 8(4), 287-296.

Niemi, Albert W. 1987. Institutional contributions to the leading finance journals, 1975 through 1986: a note. The Journal of Finance, 42(5), 1389-1397.

Novaes, Walter. 2002. Managerial turnover and leverage under a takeover threat. The Journal of Finance, 57(6), 2619-2650.

Ratner, Mitchell, \& Leal, Ricardo PC. 1999. Tests of technical trading strategies in the emerging equity markets of Latin America and Asia. Journal of Banking \& Finance, 23(12), 1887-1905.

Rocha, Daniela Torres da, Cruz, June Alisson Westarb, Azevedo, Marlon Barcelos de, Andrich, Rene Guimarães, Tardelli, Marcelo, \& Abdalla, Khalil Gibran Martins Zaraik. 2014. Finanças: Um Estudo Bibliométrico e Sociométrico da Produção Científica Brasileira. Pensar Contábil, 16(60).

Shiller, Robert J. 2013. Finance and the good society. Princeton University Press. 